\title{
Políticas para Stakeholders: um Objetivo ou uma Estratégia Organizacional?
}

\author{
Taiane Las Casas Campos
}

\begin{abstract}
Resumo
O objetivo deste artigo é discutir a fundamentação das contribuições para a construção de uma teoria de stakeholders, tendo como base a dimensão ética desse debate. Para tanto, está dividido em três partes, além desta introdução e das considerações finais. Na primeira parte são tecidas considerações quanto à dimensão descritiva e empírica do debate. Na segunda, será apresentada a teoria de stakeholders com a formulação ética implícita na proposição. Na terceira, discutimos a ética subjacente à teoria dos shareholders de forma a contrapô-la à teoria dos stakeholders. Por fim, apresentamos as proposições que buscam construir a teoria dos stakeholders a partir da convergência dos interesses dos participantes organizacionais.
\end{abstract}

Palavras-chave: stakeholders; acionistas; ética; cooperação.

\begin{abstract}
The aim of this article is to discuss the assumptions of the major theoretical perspectives for the building of a stakeholders' theory, using the ethical dimension as its groundwork. For this purpose, the article is organized in three parts, in addition to this introduction and a conclusion. In the first part, some ideas regarding the descriptive dimension of the debate are discussed. In the second part, the stakeholders' theory is presented along with the ethical explanation inherent in its proposition. In the third part, we discuss the ethic underlying the shareholders' theory in order to contrast this theory with the stakeholders' theory. Finally, we present the assumptions intended to establish the stakeholders' theory based on the organizational participants' interests.
\end{abstract}

Key words: stakeholders; shareholders; ethics; cooperation. 


\section{INTRODUÇÃO}

As relações entre as organizações e a sociedade têm se modificado, principalmente a partir dos anos 80 . Novas demandas são colocadas para as organizações, provenientes dos consumidores, dos empregados e da comunidade em geral. Estas demandas têm-se materializado, dentre outras, na maior participação das organizações em programas sociais e em novas posturas em face das necessidades dos consumidores e empregados. No Brasil, algumas dessas questões foram formalizadas pelo Código de Defesa do Consumidor, por leis ambientais e por algumas mudanças introduzidas nas relações de trabalho.

Os estudos organizacionais têm-se preocupado em entender e discutir as implicações dessas relações (Freeman, 1998). Nos anos 80, alguns passaram a discutir esta temática de forma mais ampla, sob o prisma da responsabilidade social corporativa. As dificuldades conceituais e metodológicas em delimitar a extensão da responsabilidade e a ação das organizações, nesta construção, abriram espaço para novas formulações teóricas. As preocupações, então, foram mais focadas em alguns constituintes organizacionais: consumidores, empregados, fornecedores, acionistas e a comunidade onde a organização está inserida, ou seja, nos stakeholders.

Os estudos sobre stakeholders têm sido apresentados sob ampla gama de enfoques, cujas diferenças são, basicamente, quanto ao grau de importância dos stakeholders para as organizações. Para alguns autores como Atkinson e Waterhouse (1997), Shankman (1999) e Berman e Wicks (1999) a importância dos stakeholders é determinada pelo grau de sua contribuição para o desempenho organizacional. Segundo esta proposição, o objetivo das organizações é atender a um segmento particular de stakeholders: os acionistas. Os demais são importantes na medida em que puderem contribuir para a geração de lucros. Em outro extremo, se alinham os autores como Freeman (1984, 1998), Donaldson e Preston (1995), Jones (1995), Metcalfe (1998) e Moore (1999) que consideram que o objetivo das organizações é atender aos interesses de todos os stakeholders e os acionistas são um dentre os diversos grupos de stakeholders, cujos interesses as organizações devem atender. Nessa perspectiva, não há interesses mais importantes ou mais legítimos que outros.

A partir dessas duas proposições sobre a importância dos stakeholders, ampliase o debate sobre os objetivos organizacionais e o papel dos stakeholders. Uma importante contribuição foi dada por Donaldson e Preston (1995), que mapearam 
as contribuições até então feitas sobre stakeholders e as dividiram em três dimensões: a descritivo/empírica, a instrumental e a normativa.

Na dimensão descritivo/ empírica, encontram-se os estudos que visam descrever e/ou explicar características e comportamentos corporativos em face dos stakeholders. Dentre os temas discutidos estão questões acerca da natureza da firma, como os administradores agem e o que pensam os conselheiros sobre os constituintes estratégicos (Donaldson \& Preston, 1995). Esta é uma importante dimensão da teoria e será discutida adiante.

Os estudos na dimensão instrumental objetivam avaliar o impacto dos stakeholders para o desempenho das organizações e elucidar como as estratégias e políticas que visam melhorar o atendimento aos consumidores, empregados, fornecedores e a comunidade, resultam (ou não) em melhor desempenho das organizações.

Na dimensão normativa estão as contribuições que visam "interpretar a função da corporação, incluindo a identificação da moral ou da orientação filosófica para a operação e administração das corporações" (Donaldson \& Preston, 1995, p. 65). É nesse campo que os debates se têm concentrado, pois as proposições de uma teoria para stakeholders se fundamentam essencialmente na discussão dos princípios éticos envolvidos nessa problemática.

A proposição de uma teoria de stakeholders alicerçada em bases éticas foi apresentada por Donaldson e Preston (1995). Segundo os autores, a construção de princípios morais e éticos dos negócios possibilita definir o papel e a importância dos stakeholders e, a partir daí, estabelecer a dimensão descritivo/empírica e instrumental da teoria. A proposição de uma teoria de stakeholders abre o debate quanto a sua fundamentação ética e sobre a possibilidade de contrapô-la à teoria dos shareholders. Para essa teoria, de ampla aceitação entre os economistas e muitos estudiosos organizacionais, as organizações existem para gerar lucros, de forma a remunerar os acionistas e gerar os fluxos financeiros necessários à sua sobrevivência.

O objetivo deste artigo é discutir a fundamentação das contribuições para a construção de uma teoria de stakeholders, tendo como base a dimensão ética desse debate. Para tanto, está dividido em três partes, além desta introdução e das considerações finais. Na primeira parte são tecidas considerações quanto à dimensão descritiva e empírica do debate. Na segunda, será apresentada a teoria de stakeholders com a formulação ética implícita na proposição. Na terceira, discutimos a ética subjacente à teoria dos shareholders de forma a contrapô-la à teoria dos stakeholders. Por fim, apresentamos as proposições que buscam construir a teoria dos stakeholders a partir da convergência dos interesses dos participantes organizacionais. 
Esperamos contribuir para os estudos organizacionais no sentido de aprofundar o debate sobre os stakeholders, discutindo proposições divergentes com o objetivo de ampliar o debate teórico já estabelecido. Na literatura sobre stakeholders não se percebe uma preocupação em construir argumentos que considerassem as duas perspectivas (stakeholders versus shareholders) e nosso artigo pretende contribuir na medida em que busca na filosofia, na economia e nos estudos organizacionais, o suporte teórico fundamental para apoiar a discussão do tema.

\section{Políticas Stakeholders na Dimensão Descritiva}

Uma das principais idéias defendidas por Donaldson e Preston (1995) para a construção de uma teoria de stakeholders é a de que seu objetivo é descrever situações existentes e predizer relações de causa e efeito, além de "também recomendar atitudes, estruturas e práticas que juntas constituam a administração dos stakeholders" (p. 66). O papel dos administradores, bem como sua percepção acerca da importância, dos atributos e da legitimidade dos interesses dos stakeholders, constituem a dimensão descritiva e empírica da teoria.

A primeira questão de caráter descritivo refere-se ao conceito de organizações. A teoria dos stakeholders e a dos shareholders compartilham a visão econômica de que as organizações são nexos de contratos. A visão da firma como um lócus operandi, no qual os insumos são convertidos em produtos sem "explicitar como objetivos conflitantes dos participantes individuais são trazidos para o equilíbrio, assim como os resultados são distribuídos" (Jensen \& Meckling, 1976, p. 317), dão lugar a análises que consideram a possibilidade de que o comportamento dos participantes impacta os resultados organizacionais, em especial dos administradores.

Jensen e Meckling (1976) apresentaram o conceito de organização como um nexo de contratos entre indivíduos. Como tal, a organização seria uma ficção legal, cuja existência se justifica na medida em que viabiliza contratos com os proprietários de recursos, como capital, trabalho e os consumidores. Os autores propõem um conjunto de questões a partir dessa conceituação de firma. Em primeiro lugar, por que um conjunto de relações contratuais acontece em uma organização específica? Quais as conseqüências dessas relações e quais poderão ser os objetivos das firmas? Em segundo lugar, como os administradores, enquanto elemento central dos contratos, os administram? Existem relações de preferências entre os administradores e as partes contratadas? Como os resultados da organização são distribuídos e que critérios são utilizados para definir essa distribuição? Qual a importância relativa de cada contratado? As respostas a essas formulações constituem 
as principais diferenças entre a teoria de stakeholders e a teoria de shareholders, cuja base de argumentação está centrada no direito de propriedade. Jensen e Meckling (1976) argumentam que "a especificação dos direitos individuais de propriedade é que determina como os custos e as remunerações serão alocados entre os participantes na organização" (p. 318) e "que a especificação dos direitos é geralmente efetuada pelas formas de contratação, o comportamento individual na organização, incluindo o comportamento dos administradores, irá depender da natureza dos contratos" (p. 318).

Os contratos podem assumir a forma de trocas, transações ou delegação de autoridade para a tomada de decisão ou mesmo a forma de um documento legal (Jones, 1995). A delegação de autoridade, como uma das formas contratuais presentes nas organizações oferece aos administradores as condições necessárias para gerir decisões relacionadas com todos os stakeholders.

A discussão do papel dos administradores nas relações contratuais tem sido geralmente tratada pela literatura sob o foco da teoria da agência. Uma relação de agência é "um contrato debaixo do qual uma ou mais pessoas (o principal) contrata outra pessoa (o agente) para a realização de algum serviço de seu interesse, o qual envolve delegar alguma autoridade para a tomada de decisão" (Jensen \& Meckling, 1976, p. 318).

A delegação de autoridade para a tomada de decisão decorre da separação entre a propriedade e o controle das organizações, em virtude do aumento no número de proprietários (acionistas) nas sociedades anônimas. Essa dissociação resultou no que Marris (1963) chama de empresas administradas, ou empresas que têm um administrador ou grupo em condições de decidir as questões relevantes no ambiente organizacional. Dada esta delegação de autoridade, cabe indagar quais seriam os interesses priorizados pelos administradores e como eles estabelecem as prioridades entre os diversos stakeholders.

Os interesses dos administradores são naturalmente diversificados. Williansom (1973) apresenta uma lista de motivações para realizações de suas atividades, sendo salários, segurança, status, prestigio e excelência profissional, os mais citados. O autor argumenta que essas preferências implicam na adoção de uma lógica para a alocação dos recursos organizacionais de tal forma que esses interesses sejam atendidos. Penrose (1995), Solow (1971) e Marris (1963) argumentam que a ação administrativa é voltada para o crescimento da firma e que esse objetivo, além de atender aos interesses dos acionistas, deve também proporcionar maiores salários, segurança, poder e prestigio aos administradores.

Independentemente das preferências dos administradores, Jensen e Meckling (1976) argumentam que estes têm também um dever fiduciário para com os 
acionistas, que é produto das obrigações geradas por contratos entre acionistas (contratantes) e administradores (contratados). Assim, conforme estabelecido nas relações contratuais, é função dos administradores agir no sentido de defender os interesses dos acionistas.

Por outro lado, Donaldson e Preston (1995) consideram que a responsabilidade dos administradores é "selecionar atividades e direcionar recursos para obter benefícios para os legítimos stakeholders" (p. 76). Apesar de não se estenderem na análise das implicações desse argumento, os autores consideram que os requerimentos morais para legitimar a função administrativa determinam a necessidade dos administradores de considerarem não só os interesses dos acionistas, mas de todos os stakeholders. Os administradores têm, assim, deveres multifiduciarios, baseados na crença do valor intrínseco de cada stakeholder, fundamentada em bases éticas e devem eles alocar seu esforço e os recursos organizacionais para atender aos interesses de todos os stakeholders (Moore, 1999).

\section{Políticas para Stakeholders: a Dimensão Ética}

A justificativa ética proposta por Donaldson e Preston (1995) para a administração de stakeholders é baseada na premissa de que estes têm interesses legítimos na atividade corporativa. Sendo assim, os interesses dos stakeholders têm valor intrínseco que deve ser considerado por si só e não como instrumentos para atender aos interesses de outros agentes, em especial dos acionistas.

Para legitimar os interesses dos stakeholders, Donaldson e Preston (1995) usam os mesmos princípios que justificam os interesses dos acionistas relativos ao direito de propriedade. Esse não se refere ao direito clássico de propriedade, ou seja, o direito irrestrito sobre a coisa possuída, mas ao moderno conceito de direito, baseado nas "Teorias Pluralistas do Direito". Esta teoria é fundamentada nos princípios de justiça distributiva e constitui a base para a teoria dos stakeholders, pois "todas as características críticas fundamentais da teoria da justiça distributiva estão presentes entre os stakeholders de uma corporação" (p. 72).

O princípio da justiça permeia a discussão de como os administradores deveriam considerar os interesses dos stakeholders. Freeman (1984) e Donaldson e Preston (1995) partem de uma premissa essencial, de base kantiana, de que os stakeholders devem ser considerados enquanto fim em si mesmos e não como meio para se alcançar determinados fins. A teoria da ética de Kant, de base 
deontológica (o que importa é o processo e não os resultados) parte do princípio moral de que qualquer ação dos indivíduos deve ser baseada no dever de dizer a verdade sem considerar as consequiências. A esse princípio da verdade associase o princípio da universalização, que significa que se consideramos uma ação correta para uma pessoa, ela é correta para todas as pessoas na mesma situação. Por fim, o último e mais importante imperativo categórico kantiano "aja como você trata a humanidade, se em sua própria pessoa ou como se fosse outra, sempre como fim em si mesmo, nunca como um meio" (Boatright, 1999, p. 56). Esse é um princípio de respeito às pessoas, que Freeman (1984) considera fundamental para explicar a razão pela qual os stakeholders não devem ser vistos como meio para desempenho. Esse princípio, contudo, não constitui base ética suficiente para justificar a importância e legitimidade dos interesses dos stakeholders. Freeman (1998) e Donaldson e Preston (1995) invocam então os interesses e direitos de uma estrutura ética mais contemporânea, baseada na noção de "Justiça de Rawls".

O conceito de justiça, como o do direito, é um conceito moral com amplo campo de utilização (Boatright, 1999). Na ética dos negócios, o sentido de justiça é importante para tratar a dimensão de distribuição dos benefícios da atividade produtiva. Com base na teoria da justiça, Donaldson e Preston (1995) buscam legitimar os interesses dos stakeholders e utilizam três das mais importantes teorias da justiça: o utilitarismo, o libertalismo e a teoria da justiça distributiva.

A teoria baseada na utilidade foi desenvolvida por Jeremy Bentham (17481832) e John Stuart Mill (1806-1876), que caracterizam o utilitarismo por sua fundamentação teleológica, ou seja, a ênfase está nos resultados das ações dos indivíduos (Hosmer, 1996). Uma ação é considerada correta, para os utilitaristas, se seus resultados implicam beneficio para o indivíduo. Os resultados obtidos devem ser considerados a partir dos custos incorridos e o beneficio líquido da ação é determinado pela satisfação do indivíduo, ou seja, pela utilidade, que os indivíduos agem no sentido de maximizar. A convergência da utilidade e da justiça acontece no momento em que os indivíduos, em conjunto, buscam maximizar a utilidade e determinam que sua remuneração deve ser baseada nas suas habilidades. A remuneração estabelecida dessa forma, baseada na contribuição de cada indivíduo, implica o incentivo ao desenvolvimento e melhoria do bemestar comum. Essa lógica possibilita a distribuição de bens e riqueza da sociedade a partir do princípio de que a cada um de acordo com suas habilidades (Boatright, 1999). A principal crítica ao utilitarismo refere-se à sua falta de preocupação com aspectos individuais.

A segunda vertente da teoria da justiça que Donaldson e Preston (1995) identificam é o libertarismo. Essa teoria foi desenvolvida por Nozick na década 
de 70 e tem em Friedrich Hayek e Milton Friedman seus mais importantes expoentes (Hosmer, 1996). O princípio essencial do libertarismo diz respeito ao compromisso com a liberdade individual. O padrão moral é baseado na idéia de que a qualquer um se deve assegurar grande liberdade de escolha (Hosmer, 1996). O sistema de mercado garante o sistema ético do libertarismo, na medida em que permite aos indivíduos escolher entre os cursos alternativos de ação que levam ao seu bem estar e realizar então as escolhas mais justas, certas e próprias. O princípio de justiça do libertarismo é o de que a cada um conforme suas escolhas (Boatright, 1999).

Por fim, a terceira perspectiva da justiça distributivista que Donaldson e Preston (1995) consideram para a teoria de stakeholders é o igualitarismo, cuja base foi formulada por Rawls na década de 70. Para Rawls (1998), a sociedade é uma associação mais ou menos auto-suficiente, que visa alcançar o melhor para seus membros, por meio de um conjunto de ações cooperativas, marcadas pelo conflito e pelos interesses. A identidade de interesses e a cooperação resultam em uma vida melhor para todos, se comparada com a vida possível sem cooperação. O conceito de justiça, oriundo dessa premissa, é de um "conjunto de princípios para escolha, entre os arranjos sociais, os quais determinam a divisão e a subscrição de um consenso sobre a correta estrutura distributiva" (p. 44). Dado que os indivíduos, enquanto dotados de razão, têm interesses que, muitas vezes, divergem, Rawls (1998) propõe uma sociedade que reconheça seus membros enquanto pessoas livres e moralmente iguais, capazes de criar instituições que promovam o bem-estar coletivo (Boatright, 1999). O princípio é, assim, baseado na premissa de que direitos e deveres são bem estabelecidos pela sociedade e que há uma justa distribuição dos benefícios decorrentes da mútua cooperação.

O princípio da justiça para Rawls (1998) é o da igualdade, não o do esforço ou o da habilidade, ou o da competência, mas da igualdade. Isso não significa que todos devam ter a mesma participação na distribuição dos benefícios econômicos, por exemplo, mas indica que há desigualdade se um indivíduo que cooperar mais participar menos dos resultados. Essa possibilidade é racional e livremente escolhida e é justa. Assim, uma ação pode ser considerada certa, justa e própria, se leva a maior cooperação entre os membros de uma sociedade (Hosmer, 1996). Em síntese, para Rawls (1998), o princípio de justiça é a aceitação de que a igualdade na distribuição dos benefícios assegura a cooperação social, ou seja, a cada um de acordo com sua participação.

Essas três formulações teóricas de justiça constituem o que Donaldson e Preston (1995) chamaram de Teoria Pluralista da Propriedade. Os autores argumentam que há um consenso entre estudiosos de que qualquer uma dessas teorias, isoladamente, não consegue responder às questões da justiça para os 
stakeholders. Tais formulações devem ser agrupadas para aglutinar as distintas características dos indivíduos, ou seja, "os aspectos do complexo conjunto de direitos e responsabilidades que os constituintes possuem" (Donaldson \& Preston, 1995, p. 75). Os autores consideram que várias características presentes nas teorias de justiça distributiva são também encontradas na teoria dos stakeholders. A comunidade que vive no próximo de uma fábrica tem a necessidade de ar puro. Os empregados que mantêm com sucesso uma atividade produtiva o fazem mediante seu esforço. Por fim, os consumidores têm necessidades que devem ser satisfeitas.

Freeman (1998) propõe que a base normativa da teoria seja ampliada para além da dimensão da justiça e propõe que se incorporem as dimensões de gênero e ecológica. Moore (1999) considera que a teoria de stakeholders é mais própria do constructo feminino de connected self e a teoria dos shareholders é mais masculina no sentido do individualismo, do materialismo e da competição. $\mathrm{Na}$ base normativa ecológica, Freeman (1998) propõe que administradores possam agir no sentido de cuidar da terra e Moore (1999) conclui que esses cuidados poderão levar a elevados retornos sociais para todos os stakeholders, além de o planeta ser protegido e preservado. Assim, o debate sobre stakeholders, na base normativa, deveria considerar que as organizações visam produzir riqueza, não apenas lucros. A riqueza deve ser distribuída de forma justa e gerada num contexto que considera as relações pessoais, com o ambiente e com a sociedade (Moore, 1999).

A questão que emerge desse debate se refere à possibilidade de que a administração de stakeholders, justificada por princípios éticos, de gênero ou ecológicos, seja factível. Segundo Metcalfe (1998) a "instância ética não e alcançável se não é mais que um sonho" (p. 33) e as possibilidades desta dimensão estão baseadas nas mudanças dos métodos de governança corporativa. A estrutura de governança existente atualmente nas organizações privilegia os interesses dos shareholders, pois são os representantes destes que estão no poder. A possibilidade de mudanças viria, então, de uma administração de stakeholders imposta pela ação regulatória governamental. Apesar de essa possibilidade estar presente, por exemplo, com a implantação do Código de Defesa do Consumidor e de toda uma legislação ambiental no Brasil, não parece possível que a ação governamental possa regular toda a gama provável de ações empresariais. A alternativa possível e provável para a existência de uma administração ética de stakeholders, segundo Metcalfe (1998) seria, então, a implantação de uma política de auto-regulação das organizações.

Mesmo que as organizações se inclinem a adotar uma política que privilegie os interesses dos stakeholders, isto não assegura, na teoria proposta por Donaldson 
e Preston (1995) e Freeman (1998), que todos sejam contemplados de forma justa. Os princípios de justiça do utilitarismo - a cada um de acordo com suas habilidades-, do libertarismo - a cada um de acordo com suas escolhas - e da justiça distributiva - a cada um de acordo com sua participação não estabelecem como as organizações podem ou devem distribuir seus resultados para o alcance desses preceitos. A teoria não prevê como interesses divergentes e, muitas vezes, conflitantes são atendidos no contexto organizacional. Os consumidores podem considerar que um preço mais baixo seja justo, o que determinaria menores salários. Os empregados podem valorizar suas habilidades, participação e esforço e esperar salários maiores, acarretando preços maiores e lucros menores. Caberia então aos administradores arbitrar como os resultados deveriam ser distribuídos.

Donaldson e Preston (1995) não consideram, na teoria proposta, a condição de distribuição dos recursos no ambiente da organização, mas de preceitos éticos para sociedade de maneira mais geral. As questões de como e quem, na organização, têm legitimidade e prerrogativas para determinar como os resultados organizacionais devem ser distribuídos não são endereçadas por esta perspectiva teórica.

\section{A Teoria dos Shareholders: a Contraposição}

A justiça distributiva que permeia a proposição teórica de Donaldson e Preston (1995) também oferece a fundamentação necessária para se pensar em uma organização voltada aos interesses dos acionistas. Essa é a base da dimensão instrumental ou administração estratégica de stakeholders. Esses são considerados na medida em que influenciam os resultados, ou seja, os lucros, a taxa de crescimento, dentre outros. Nessa vertente, as organizações não têm o objetivo primário de atender aos stakeholders em seu conjunto, mas a grupos de stakeholders em particular, os acionistas. Os demais stakeholders são, então, um meio para atender a um grupo especifico e não um fim em si mesmo.

Friedman (1998) apresenta uma contundente defesa no sentido de que o objetivo das organizações é maximizar o capital investido pelos acionistas. Para ele, quem tem responsabilidade social são os indivíduos, não as organizações. $\mathrm{O}$ administrador, enquanto contratado pelos proprietários, deve ser responsável pelos empregados e pela condução geral dos negócios e, enquanto executivo da organização, não cabe a ele desenvolver ações relacionadas à responsabilidade social corporativa, pois esta é uma dimensão privada. Como a organização é uma instituição econômica e enquanto tal é avaliada pelo mercado, qualquer política adotada pelo administrador, que contemple indivíduos em detrimento do desempenho, gera duas 
conseqüências: 1 . um custo adicional que implica perda de lucratividade e perdem todos (consumidores, fornecedores e empregados); e 2. arbítrio do administrador, que terá que estabelecer prioridades em relação ao beneficiários. Responsabilidade social seria uma prerrogativa dos governos, únicos agentes que têm legitimidade para estabelecer os beneficiários de qualquer ação social. Friedman (1998) afirma ainda que o objetivo das organizações é o lucro e, na medida em que são administradas com este fim, há ou são gerados ganhos para toda a sociedade.

Para Penrose (1995), Solow (1971) e os economistas neoclássicos, o objetivo das organizações é tão somente maximizar os lucros, pois esta é a forma mais eficiente de conduzir os negócios. Dessa discussão emergem duas questões importantes para a contraposição com a teoria de stakeholders. Em primeiro lugar, é necessário estabelecer as bases que justificam a busca pelo lucro como a forma mais eficiente de organização da atividade econômica e administrativa para a sociedade. Em segundo lugar, é necessário justificar por que os acionistas, detentores dos lucros, têm direitos sobre eles. Implica saber por que as organizações devem ser administradas visando atender aos interesses não de todos os stakeholders, mas de um grupo em particular, isto é, os acionistas.

A eficiência econômica gerada pela busca do lucro deve ser estabelecida a partir da teoria microeconômica, pois esta é "na sua forma completa mais uma teoria da sociedade que uma teoria descritiva da firma" (Hosmer, 1996, p. 33). A teoria microeconômica neoclássica é baseada nos princípios utilitaristas. $\mathrm{O}$ utilitarismo, diferentemente das outras escolas de ética, possui caráter teleológico. Isso implica o exame dos resultados da ação humana e não o processo, como enfatizam as escolas deontológicas. O principio básico do utilitarismo é o de que "uma ação é correta se e somente se ela produz o melhor balanço de prazer acima da dor para qualquer um" (Boatright, 1999, p. 95). A busca da sociedade é pelo bem estar comum e as contribuições das ações individuais devem se dar-se neste sentido. A utilidade de uma ação é medida pelo balanço entre prazer ou felicidade e dor ou não felicidade.

O utilitarismo apresenta três princípios (Boatright, 1999). O primeiro é o consenqüencialismo, isto é, as ações são determinadas por suas consequiências. O segundo é o maximalismo ou uma ação é considerada correta não somente se tem boas conseqüências, mas se apresenta a melhor conseqüência possível, quando outras também são possíveis. Por fim, o universalismo avalia as consequiências sobre a sociedade como um todo. Estes princípios geram o que Hosmer (1996) chama de uma teoria larga da sociedade, sob a ótica da alocação eficiente dos recursos escassos.

A partir dos princípios utilitaristas, os economistas construíram a teoria de alocação de recursos, ou seja, dos fatores de produção (capital e trabalho) que, 
convertidos em produtos, atendem aos consumidores e resultam na geração de lucros para os empresários. Essa estrutura culmina em uma situação de equilíbrio denominada Ótimo de Pareto (Varian, 2000).

O Ótimo de Pareto refere-se à condição em que os recursos escassos são usados tão eficientemente pelas firmas e os bens e serviços são distribuídos tão eficientemente pelos mercados competitivos, que é impossível fazer qualquer pessoa melhor sem que outra pessoa seja prejudicada (Hosmer, 1996).

Essa condição de eficiência é resultado do fato de que o sistema econômico, através do mercado competitivo, é capaz de: 1 . fornecer aos consumidores os bens e serviços em quantidades e preços que satisfaçam suas necessidades, considerando sua renda; 2 . considerando os preços de mercado, as firmas alocam os fatores de produção, capital (maquinas e equipamentos) e trabalho em combinações que maximizam as quantidades de produtos, sendo esta a quantidade que os consumidores desejam, considerando os preços. As firmas remuneram os fatores de produção conforme seu produto marginal, ou seja, sua contribuição para o processo produtivo. A condição do Ótimo de Pareto advém do fato de que, se qualquer destes componentes não for administrado eficientemente, irá gerar perda de bem-estar a um ou a todos os participantes. Se os salários pagos forem maiores que o produto marginal do trabalho, os preços dos bens e serviços se elevarão, gerando perda de bem estar para os consumidores e redução nos lucros.

Os lucros, nessa estrutura, são a remuneração dos empresários pela contribuição e riscos assumidos em relação à atividade produtiva. Os mercados são perfeitamente competitivos e o aumento dos lucros ou salários implica a elevação dos custos e a perda de mercado para os concorrentes. Assim, os lucros são aqueles necessários para motivar a ação empresarial e são igualmente possíveis para todos os empresários daquele setor. A maximização dos lucros, ou seja, a diferença entre receitas e despesas, gera uma situação de eficiência para todos os envolvidos. As receitas são determinadas pela quantidade produzida e pelos preços. Como os preços não são, neste modelo, determinados pelas firmas, mas pelo mercado, as possibilidades de maximização dos lucros estão condicionadas à redução dos custos, ou seja, à eficiente alocação da mão de obra, à incorporação de tecnologia e a outros fatores de custo sujeitos à ação do empresário. Dessa forma, não há lucro econômico puro e sim aqueles obtidos pela eficiente atuação empresarial.

A principal critica ao modelo microeconômico das firmas refere-se à inexistência de mercados tão perfeitamente competitivos. Como há a presença de oligopólio (poucas firmas dominam o mercado) ou monopólio (uma única firma domina), os mercados são, na verdade, imperfeitos. No caso do oligopólio, os lucros seriam 
maiores que em mercados concorrenciais, mas em níveis suficientes para manter a concorrência. No caso do monopólio, contudo, os lucros podem ser de qualquer ordem e só há situação de monopólio, se houver uma restrição legal para a entrada de novos concorrentes (Varian, 2000).

Em síntese, quando os economistas e notoriamente Friedman (1998), afirmam que a busca pelo lucro é a forma mais eficiente de organização da atividade econômica e de atender aos interesses dos stakeholders. Isto significa que só a busca pelo lucro gera a possibilidade de alocar os recursos de forma eficiente, ou seja, em atender os interesses dos consumidores, dos empregados, dos acionistas e dos fornecedores conjuntamente.

A segunda questão que a administração estratégica de stakeholders suscita está relacionada à legitimidade dos acionistas, enquanto grupo que a organização visa atender. Os direitos dos acionistas são garantidos pelo instituto da propriedade privada, que "não é uma coisa tangível igual à terra, mas um conjunto de direitos que definem o que um proprietário ou entidade pode fazer com a coisa" (Boatright, 1999, p. 349). A propriedade implica a posse da coisa possuída e pressupõe responsabilidades sobre ela. Com a separação de propriedade de controle nas organizações e o crescimento das sociedades anônimas, a propriedade é dos agentes que investem seus recursos nos negócios, mas o controle passa às mãos dos administradores.

As organizações, conforme discutido, são nexos de contratos que buscam nos mercados os recursos necessários à sua sobrevivência. Garantias são dadas de que os contratados não terão seus recursos expropriados e que a remuneração pelo uso dos recursos será a mais justa possível. Todos os contratados têm estas garantias, menos os provedores de capital, ou seja, os acionistas. O retorno do capital investido acontece no fim do processo, diferentemente dos demais contratados (empregados, fornecedores, consumidores) que têm garantias de não expropriação ao longo do processo, enquanto a organização for solvente. Os acionistas, por sua vez, assumem os riscos residuais da condução dos negócios (Boatright, 1999) e o retorno do capital investido é de valor incerto e condicionado à condução eficiente dos negócios. Os riscos dos acionistas são maiores na medida em que eles próprios se afastam da condução dos negócios. Uma forma de reduzir os riscos, segundo Boatright (1999), é garantir algumas prerrogativas de controle, de forma que os majoritários possam nomear e destituir os diretores e eleger o Conselho de Administração.

Nessa linha de raciocínio, é possível definir um padrão de eficiência para os lucros e o crescimento da riqueza organizacional, considerando que os acionistas se reservam o controle da organização. Como os acionistas são a única parte do nexo de contratos para os quais os rendimentos não são fixos, interessa a eles e 
somente a eles que os resultados sejam maximizados. Os demais participantes dos negócios tendem somente a assegurar os seus retornos fixos; somente aos acionistas interessa alocar eficientemente os recursos organizacionais de forma a maximizar as diferenças entre receitas e despesas.

\section{Políticas para STakeholders: A CoOperaçÃo}

Jones (1995) organiza o debate acerca das políticas para stakeholders. Em primeiro lugar, lembra que as firmas são nexus de contratos, entre elas e seus stakeholders. Os administradores representam a parte contratante e ao mesmo tempo contratada, ou seja, são também stakeholders. A esse propósito, Jones lembra Williansom (1981), que reconheceu esse dilema, ao considerar que os administradores fazem os contratos com uma mão e o assinam com a outra. Administradores são tecnicamente stakeholders, mas suas funções básicas são as de contratantes dos demais stakeholders, o que não significa que esses agentes tenham o controle da organização. Embora os administradores tomem importantes decisões, o controlador detém importantes mecanismos de controle, tais como o sistema de remuneração e de incentivos. Também a existência dos conselhos de administração, como órgão regulador das relações entre proprietários e gestores, pode alinhar, em alguma medida, os conflitos de agência. Assim, para a construção de uma teoria sobre stakeholders, é possível considerarmos os administradores e as firmas como uma entidade única, que irá estabelecer os contratos com os demais stakeholders.

Para entender as condições dos contratos estabelecidos entre as organizações e os stakeholders, Jones (1995) se baseia em duas teorias. A primeira é a teoria da agência, que estabelece as premissas comportamentais dos participantes organizacionais e, conforme já discutido, as condições contratuais entre os agentes e o principal. O contrato eficiente é aquele que minimiza os custos de agência, ou seja, os custos de elaboração e monitoramento dos contratos. A segunda estrutura teórica utilizada por Jones (1995) é a dos custos de transação, uma vez que as políticas para stakeholders poderiam gerar vantagens competitivas que resultariam em redução dos custos de transação.

A partir da teoria da agência, no que se refere ao comportamento racional e oportunista dos participantes organizacionais e às especificidades e custos do processo de trocas, Jones (1995) fundamenta uma teoria instrumental de stakeholders. A premissa fundamental é a de que as organizações, inseridas em mercados competitivos, devem elaborar contratos eficientes. 
Os contratos eficientes são aqueles em que os benefícios gerados são maiores que os custos de execução e monitoramento para as partes contratantes. Em condições de equilíbrio no sentido do Ótimo de Pareto, os contratos tendem a ser eficientes, pois os mercados pressionam nesse sentido e punem quem contrata de forma ineficiente. Contudo, em estruturas sem concorrência, ou seja, em condições de concorrência imperfeita, é possível a vigência de contratos ineficientes por longo período de tempo, dependendo do poder de elaborar e monitorar contratos pelas partes envolvidas (Jones, 1995).

As pesquisas que avaliam as condições de elaboração e execução de contratos eficientes se dividem em duas vertentes. Na primeira, estão os autores que se propõem a avaliar os mecanismos que objetivam reduzir o oportunismo dos agentes. Esses mecanismos referem-se aos incentivos, ao monitoramento e às estruturas de governança que coíbem ou minimizam a ação oportunista dos agentes, sejam eles administradores, empregados, fornecedores ou quaisquer grupos de stakeholders. Na segunda vertente das pesquisas sobre contratação eficiente, estão as contribuições que buscam identificar os mecanismos existentes para reduzir o comportamento oportunista, a partir da "adoção voluntária de padrões de comportamento que limitam ou eliminam esse tipo de comportamento" (Jones, 1995, p. 8). Para esse autor, os custos de agência e custos de transação podem ser reduzidos, quando os participantes agem baseados na mútua cooperação, o que reduz os custos de elaboração, monitoramento e a necessidade de garantias das relações contratuais. Contudo, os ganhos ou remunerações provenientes do oportunismo são imediatos e aqueles advindos da mútua cooperação são distantes no tempo e de difícil quantificação. Restaria a questão acerca do que determina que agentes racionais ajam de forma cooperativa e o tipo de racionalidade que esse comportamento encerra.

Para Hussey (2000), não existe contradição entre o comportamento racional baseado no auto-interesse e aquele baseado na cooperação. Haveria, em primeiro lugar, os sentimentos morais dos quais são dotados os indivíduos, tais como amor, culpa, lealdade, honestidade e justiça. O comportamento baseado nos sentimentos morais, ou seja, aquele que possibilita a mútua cooperação é racional, pois possibilita resolver os problemas de compromisso entre indivíduos (commitment problems). Esse tipo de problema está presente em situações de negociação em que é geralmente vantajoso, para ambas as partes, buscarem a cooperação ao invés de atuar oportunistamente. Embora as partes, em uma negociação, possam ter vantagens materiais em fraudar ou enganar, os custos de transação de negociações futuras podem superar os benefícios advindos com o rompimento do compromisso. Os ganhos advindos da solução dos problemas de compromisso são demonstrados na teoria dos jogos, quando se percebe claramente que, em jogos não repetitivos, os jogadores tendem a buscar os ganhos advindos da ação não cooperativa, 
enquanto em jogos repetidos, os problemas de compromisso se tornam evidentes e os jogadores ganham, se buscarem a cooperação (Jones, 1995).

As negociações entre as organizações e seus stakeholders são contínuas e a existência de problemas de compromisso impõe a necessidade de se reduzir o oportunismo em favor da cooperação. Jones (1995) considera que a presença de sentimentos morais, em especial da honestidade e da justiça, é relevante para reduzir os custos de agência e os custos de transação.

A manifestação da existência de sentimentos morais se expressa, segundo Hussey (2000), por maneiras sinceras e/ou pela reputação. As maneiras sinceras são manifestações físicas, tais como forma de olhar, gestos faciais dentre outros, que indicam às partes em negociação o nível de disposição para a cooperação. A reputação refere-se ao comportamento passado e demonstra a existência de sentimentos morais. O comportamento baseado em sentimentos morais, em especial a honestidade e justiça, aumenta a probabilidade de que esse tipo de comportamento se repita no presente e no futuro (Hussey, 2000). Essa é uma importante informação para as partes em negociação, pois reduz a incerteza e o oportunismo nas transações.

Contudo, conforme lembra Jones (1995), o comportamento ético baseado em sentimentos morais é da esfera do indivíduo e nada garante que esse tipo de comportamento seja transladado para as organizações. Para que as organizações tenham o benefício do comportamento ético, é necessário demonstrar que seu comportamento reflete o sentimento moral dos administradores, o que fornece significado à moralidade corporativa .

A moralidade é definida por Vasques (1975, p. 52) como "o componente efetivo das relações humanas concretas, ou ainda, constitui um tipo específico de comportamento dos homens e, como tal, faz parte de sua existência". A moralidade é a moral em ação, ou seja, a materialização de preceitos morais das sociedades. A moralidade corporativa é o reflexo dos padrões éticos dos administradores que é imposta aos demais participantes organizacionais e reflete em seu comportamento. A moralidade corporativa é estabelecida, em primeiro lugar, por meio das maneiras sinceras e da reputação e em segundo lugar, pelas políticas e decisões das organizações em relação aos seus stakeholders (Jones, 1995).

As políticas para stakeholders, tais como pagamento de benefícios, política salarial, políticas ambientais e outras decididas pelos executivos e executadas pelos demais participantes organizacionais, são visíveis por afetar os stakeholders e determinar a reputação das organizações. A reputação das organizações, por sua vez, é reflexo da reputação dos administradores e é continuamente testada pelas decisões e políticas para stakeholders. Segundo Jones (1995), a reputação 
pode tornar as negociações menos custosas em termos de elaboração, monitoramento e das sanções legais previstas nos contratos. Dessa forma, organizações que agem com base em sentimentos morais, que são refletidas em suas maneiras sinceras e em sua reputação, têm vantagens competitivas sobre as demais, pois reduzem seus custos de transação e de agência.

Com essas proposições, Jones (1995) estabelece as premissas para uma teoria instrumental de stakeholders, cujas bases estão na economia organizacional, ou seja, na teoria da agência e de custos de transação e na ética do comportamento. $\mathrm{O}$ autor considera que o oportunismo nas relações entre as organizações e seus stakeholders inviabiliza a obtenção das vantagens competitivas advindas do comportamento baseado na mútua cooperação. O oportunismo aumenta os custos de agência e de transação, enquanto a mútua cooperação gera vantagens competitivas por eliminar o oportunismo. Hussey (2000) lembra que as ações baseadas em sentimentos morais são racionais: podem fazer parte das preferências dos indivíduos e reduzem o oportunismo dos agentes.

A teoria instrumental de stakeholders de Jones (1995) mantém a premissa comportamental da economia organizacional de que os agentes são racionais, porém essa racionalidade é limitada, além de incorporar preceitos éticos em relação ao oportunismo. A supressão do oportunismo é o determinante para geração de vantagens competitivas que as organizações obtêm em suas relações com stakeholders. Diferentemente das proposições da teoria normativa de stakeholders proposta por Donaldson e Preston (1995), a teoria de Jones (1995) busca na ética somente os determinantes de comportamento não oportunista. Esse comportamento pode fazer parte do cálculo estratégico dos indivíduos e organizações ou pode ser inerente ou intrínseco a eles.

\section{Considerações Finais}

As discussões acerca dos objetivos das organizações podem dar-se em duas instâncias. Em primeiro lugar, pode-se pensar em metas ou resultados que devem ser perseguidos e obtidos, de forma que se garanta a continuidade dos negócios. Esse é o nível de análise comumente encontrada nos estudos organizacionais. Em segundo lugar, pode-se pensar em como estes resultados são distribuídos, quais são os objetivos dos constituintes organizacionais, seus interesses e legitimidade.

As proposições de Freeman (1984, 1998), Donaldson e Preston (1995) se concentram nesta segunda vertente. Esses autores discutem a legitimidade dos diversos interessados nos negócios de dimensão ética, pois equiparar os acionistas 
aos empregados, fornecedores e consumidores só é factível nesta dimensão. $\mathrm{Na}$ dimensão legal, administrativa ou econômica, estes agentes têm papéis, interesses e participações diferentes. Enquanto os empregados, fornecedores e consumidores têm sua participação nos negócios já estabelecida por contratos feitos a priori, os acionistas dependem dos resultados gerados no final do processo. Enquanto os stakeholders são partes contratadas, os acionistas são parte contratante. Contudo, nas proposições de Donaldson e Preston $(1995)$ e Freeman $(1984,1998)$ e de grande número de estudiosos da teoria dos stakeholders, deve-se discutir a legitimidade destes interesses no contexto de stakeholders como um fim e não como o meio para alcançar outros fins. Esta forma de pensar as organizações, apesar de apresentar grande apelo moral, não apresenta proposições operacionais ou administrativas e não conclui se esta proposição constitui uma proposta de condução ideal das organizações ou se retrata mais a realidade de sua estrutura.

A construção de uma teoria de stakeholders a partir de uma estrutura normativa é importante, pois considera as dimensões éticas no ambiente organizacional. $\mathrm{O}$ caráter pouco pragmático dessa vertente, contudo, dificulta novas construções nesse campo. As contribuições de Jones (1995) para uma teoria baseada na cooperação, por outro lado, ampliam o escopo de análise acerca de como e por que os interesses dos stakeholders devem ser considerados pelos gestores organizacionais. Nesse contexto, os gestores deveriam considerar em suas decisões não somente os interesses dos shareholders, mas também dos stakeholders, se não por dever ético, já que este é da esfera do indivíduo, mas porque esse comportamento implicará a redução dos custos de agência e transação.

As proposições de Jones abrem espaço para as pesquisas empíricas e conferem à teoria de stakeholders uma dimensão crítica e empírica capaz de consolidar nos estudos organizacionais um campo importante de conhecimento sobre as relações das organizações com seus mais importantes constituintes estratégicos.

\section{Artigo recebido em 19.07.2004. Aprovado em 19.01.2005.}

\section{ReferênCIAS Bibliográficas}

Altkinson, A. A., \&

Waterhouse, J. (1997, Spring).

A stakeholders approach to strategic performance measurement. Sloan Management Review, 38(3), 25-36.
Berman, W. (1999, October)

Does Stakeholder Orientation Matter? The Relationship between Stakeholder Management Models and Firm Financial Performance. Academy of Management Journal, 42(5), 488-506. 
Boatright, J. R. (1999). Ethics and the conduct of business (3rd ed.). New Jersey: Prentice Hill.

Donaldson, T., \&

Preston, L. (1995. January).

The stakeholders theory of the corporation: concepts, evidence and implications. Academy of Management Review, 20(1), 65-91.

Freeman, E. R. (1998).

A stakeholders theory of the modern corporation. In L. P. Hartman Perspectives in business ethics. New York: McGraw-Hill International Editions.

Freeman, E. R. (1984).

Strategic Management- A Stakeholder Approach. London: Pitman Publishing.

Friedman, M. (1998).

The social responsibility of business is to increase its profits. In L. P. Hartman Perspectives in business ethics. New York: McGraw-Hill International Editions.

Hosmer, LaRue T. (1996).

The Ethics of Management (3rd ed.). Boston: Irwin McGrow- Hill.

Hussey, R. (2000).

La solidaridad frente a la racionalidad económica en algunos autores recientes. In J. O. Schneider (Org.). Economia e ética. Rio Grande do Sul: Editora Unisinos.

Jensen, M., \&

Meckling, W. (1976, October).

Theory of the firm: managerial behavior, agency costs and ownership structure. Journal of Financial Economics, 3(4), 305-60.
Jones, T. M. (1995, January).

Instrumental stakeholders theory: a synthesis of the ethics and economics. Academy of Management Review, 20(2), 404-437.

Marris, R. (1963).

The Theory of the Growth of the Firm. London Oxford University Press.

Metcalfe, C. E. (1998, January).

The stakeholders corporation. Business Ethics: A European Review, 7(1), 30-36.

Moore G. (1999, April).

Tinged shareholders theory: or what's so special about stakeholders? Business ethics: A European Review, 8(2), 117-127.

Penrose, E. (1995).

The theory of the growth of the firm. New York: Oxford University Press.

Rawls, J. (1998).

The theory of justice distributive. In L. P. Hartman (Ed.). Perspectives in Business Ethics. New York: McGrawHill International Editions.

Shankman, N. A. (1999, May).

Reframing the debate between agency and stakeholders theories of the firm. Journal of Business Ethics, 19(4), 319-334.

Solow, R. M. (1971).

Some implications of alternative criteria for the firm. In R.L. Marris, \& A. Wood (Ed.). The corporate economy- growth, competition and innovative potencial. Cambridge, mass: Harvard University Press. 
Varian, H. (2000).

Microeconomia: princípios básicos - uma abordagem moderna. Rio de Janeiro: Campus.

Vasques, A. S. (1975).

Ética. Rio de Janeiro: Civilização Brasileira.
Williamson, O.E. (1981).

The economics of organization: the transaction cost approach. American Journal of Sociology, 84(3), 549-577.

Williamson, O.E. (1973).

Managerial discretion and business Behaviour. In Gilbert M. Gilbert (Ed.). The modern business enterprise. London: Penguin Books. 